Research Article

\title{
Experimental Study of the Shear Performance of Scrap Tire-Granular Material Composite Columns
}

\author{
Fengchi Wang $\mathbb{D},{ }^{1}$ Xiaomei Nie, ${ }^{2}$ Hanyu Zhao, ${ }^{2}$ and Haiming $\mathrm{Hu}^{3}$ \\ ${ }^{1}$ School of Transportation Engineering, Shenyang Jianzhu University, Liaoning 110168, China \\ ${ }^{2}$ School of Civil Engineering, Shenyang Jianzhu University, Liaoning 110168, China \\ ${ }^{3}$ Shenyang Jianzhu University Library, Shenyang Jianzhu University, Liaoning 110168, China
}

Correspondence should be addressed to Fengchi Wang; cefcwang@sjzu.edu.cn

Received 6 September 2019; Accepted 21 April 2020; Published 8 May 2020

Academic Editor: Lukasz Sadowski

Copyright (c) 2020 Fengchi Wang et al. This is an open access article distributed under the Creative Commons Attribution License, which permits unrestricted use, distribution, and reproduction in any medium, provided the original work is properly cited.

Scrap tires filled with granular materials can be used for geotechnical engineering. However, when subjected to earthquakes and other conditions, shear failure occurs between the tires. In this paper, eight groups of tire-sand composite columns are prepared and tested under shear strength tests. Different vertical forces, sand densities, and loading modes are considered to investigate the shear performance. The failure patterns, load-displacement curves, and stress-strain curves are observed. The results show that the shear failure of composite undergoes three typical stages: overall flexural lateral displacement, transverse compression, and relative interfacial slip. Under monotonic loading, the restriction of the transverse deformation of the composite column is enhanced with increasing vertical force. The overall antidisturbance ability of the composite is enhanced with increasing sand density. The cyclic loading mode can improve the lateral stiffness of the tire-sand composite. The relative motion between the tiresand interfaces has two forms: elastic creep and interface sliding. Under the hoop effect of the tire, the pores between the particles produce a pseudocohesive force, which causes the shear strength of the tire-sand composite to be higher than that of common sand. A formula is obtained to describe the stress-strain variations in the composite under different vertical forces.

\section{Introduction}

Scrap tires are called "black pollution" because of their large quantity and lack of degradation under natural conditions. The disposal of these scrap tires has become an international socioeconomic and environmental issue [1]. With the increasing shortage of land resources, it is not feasible to bury waste tires at will. However, stockpiling of scrap tires is also undesirable because of the potential fire hazard and consequent environmental damage [2].

There are two main ways to recycle scrap tires: one is to shred or breakdown the tires by secondary processing into rubber particles or chips, which can be used as an admixture [3]; the other is to use the whole tire directly [4]. The durability of whole tires makes them particularly attractive for use. In particular, the use of tires without shredding or breaking them down into tire chips is desirable because energy is not wasted in further processing of this waste material. Such structures can avoid impacts on the environment. At present, the percentage of scrap tires recycled is not compatible with the growth in the number of scrap tires [5]. The world produces approximately 17 million tons of scrap tires per year, which eventually turn into waste tires [6]. Approximately $64 \%$ of the waste tires were sent to landfills, and only $13 \%$ of them were recycled [7]. Only $5 \%$ of the recycled waste tires are used in construction [8]. It is estimated that the number of used tires has exceeded 13 million tons in China and will continue to rise along with the rapid growth of the automobile industry [9].

In their whole form, scrap tires are directly used in crash barriers [10], slope reinforcement [11], retaining walls [12], reinforced soil foundations [13], and in many other potential applications (Figure 1), especially in reducing settlement and improving stability. Kang and Zhang [14] analyzed the scrap tires directly reclaimed and reused application in landscape engineering. It is suggested that old tires can be used in 


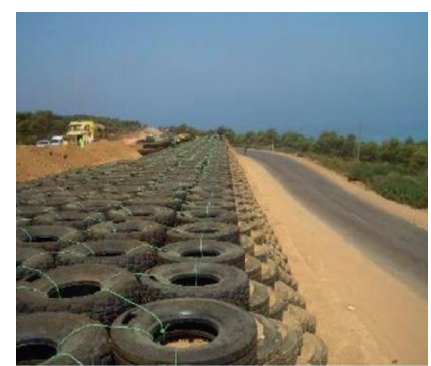

(a)

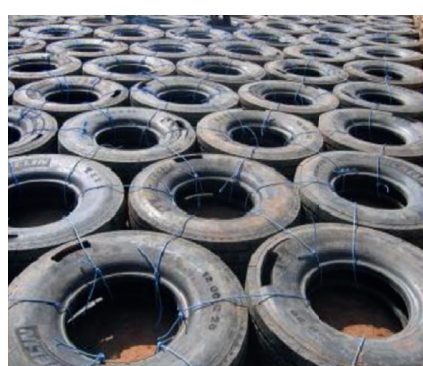

(b)

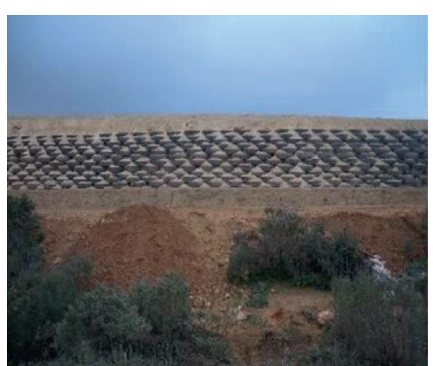

(c)

FIGURE 1: The reinforced applications using scrap tires.

simple, cost-effective, and environmentally friendly way. Environmental considerations would indicate that the use of whole tires or tires with one sidewall removed embedded in soil may be preferable to the use of tire chips [15]. The growing interest in utilizing waste materials in civil engineering applications has opened the possibility of constructing reinforced soil structures with unconventional backfills. [16] After the Wenchuan earthquake in China, the landslide after the earthquake was treated by the technology of reinforcing retaining walls with waste tires and ecological slope protection [17]. Sayão et al. [18] built a $60 \mathrm{~m}$ long prototype soil-tire retaining wall with layers of tires filled with compacted soil. The soil-tire interaction mechanism was studied by a series of field pull-out tests with several arrangements of scrap tire mats that were subjected to different confining levels. The research revealed that scrap tires are an attractive low-cost construction material for slope-stabilization projects. An innovative and inexpensive slope-stabilization scheme was presented by Poh and Broms [19]. Rubber tires were filled with granite aggregate and quarry waste and used for construction of a wall. The total cost was less than $40 \%$ of the estimated cost of a conventional retaining wall. Garga and O'Shaughnessy [20] tested approximately 10000 whole tires and tires with one sidewall removed, tied together with polypropylene rope, in retaining walls and slope reinforcement. The test results showed that the lateral deformation of the wall section constructed with whole tires was significantly larger than that with cut tires (one sidewall removed). The lateral displacements of walls using whole tires filled with sand were approximately $60 \%$ larger than those measured in the cut tire wall section. O'Shaughnessy and Garga [21] performed a large number of pull-out tests on whole tires and tires with one sidewall removed embedded in sand and cohesive backfill. The test results showed that the pull-out resistance of tire mat reinforcement was primarily governed by the effective shear strength of the soil, and therefore it can provide an efficient means of reinforcement. A series of field-scaled pull-out tests were carried out by Kim et al. [22] to investigate the pull-out behavior of cell-type tires in reinforced soil structures. The results showed that the ultimate pull-out resistance of cell-type tires was approximately 1.25 times that of the geocell reinforcement. The treads and sidewalls of tires were combined by Yoon et al. [23] to make a tire mat as a reinforcing material in sand. Plate load tests were conducted to study the reinforcing effect under various conditions of the tire segments. The effects of reinforcement and settlement reduction are higher at lower sand densities. The reinforced sand's bearing capacity is more than twice that of unreinforced sand. The combinations of both treads and sidewalls resulted in the highest bearing capacity.

If the bearing capacity of the foundation cannot meet the requirements under the action of the building load, the foundation will incur local or overall shear damage, which will affect the safety and normal use of the building and even cause the destruction of the building. The bearing capacity of a natural foundation is mainly related to the shear strength of the soil. In the construction of an embankment and retaining wall, the whole tire or tire with one sidewall removed can be used as building material to solve the problem of low shear strength of the original soil layer. Scrap tires can effectively replace the original building material made of nonrenewable resources (e.g., geosynthetics) [24]. The performance of retaining walls under static and seismic loading conditions depends upon the type of backfill soil; generally, clean granular cohesion with less backfill material is preferred. However, new lightweight fill materials, such as shredded tire chips, are currently being explored as alternative backfill materials [25]. These materials are beneficial in reducing earth pressures on and lateral displacements of retaining walls [26]. Discarded tires used with other stabilization materials to reinforce an unstable highway shoulder or protect a channel slope have remained stable. Discarded tires were banded together and partially or completely buried on unstable slopes. Construction costs were reduced from 50 to $75 \%$ of the lowest cost alternatives, such as rock, gabion (wire mesh/stone matting), or concrete [27]. The road embankment was rebuilt by reinforcing the soil with tire sidewall mats that were vertically spaced at $0.6 \mathrm{~m}$. The individual tire sidewalls were joined together by steel clips to form a continuous mat, which resulted in saving of some expensive fill [28]. Scrap tires with one sidewall (top side) removed for better soil compaction were tied together with polypropylene rope into a mat configuration and staggered layer by layer. The tire-reinforced scheme had good slope repair performance and reduced the cost of materials and construction [29]. Wang et al. [30] proposed the use of scrap tires to constrain the granular material and form scrap-tire columns (STCs) with good bearing capacity, which transforms the tensile strength of a discarded rubber tire into a 
hoop-tightening force on granular sand soil, that is, hoop capacity. Lu et al. [31] preliminarily investigated the feasibility of STC-reinforced sand for horizontal and vertical damping. Wang et al. [32] investigated the effect of the filler type on the cyclic shear behavior of STC-reinforced geomaterials. It was found that the inside filling geomaterials significantly affect the energy dissipation and that the scrap tires mainly act as reinforcements.

After compaction with granular materials, scrap tires can be used for foundation treatment and retaining walls. When subjected to earthquakes, landslides, and other effects, there will be relative dislocation between the tire layers, which will cause shear failure of the foundation or retaining wall. Therefore, it is very important to evaluate the material characteristics of the backfill and the interface behavior between the backfill and tire rubber. In this paper, three tire units overlap to form a cylindrical composite column. The unit in the middle is the test unit. The horizontal displacement of the two adjacent units above and below is fully constrained, and two shear interfaces are formed among them. The shear behavior of the composite column was performed with different vertical forces, density, and loading modes under monotonic load and cyclic load.

\section{Experimental Program}

2.1. Test Materials and Specimens. The properties of natural sandy soil and gravel soil are quite discrete. To ensure the repeatability of the test, Xiamen standard sand (according to national standard GB/T17671-1999), as shown in Figure 2(a), is used as granular material to fill the interior of scrap rubber tires. The test tires are discarded by taxis. The specific model is 185/60R14, as shown in Figure 2(b), and the specific size is shown in Figure 2(c). To ensure the accuracy and stability of the test results, the scrap tires are of the same brand, and the degree of wear is approximately the same. The texture depth of the scrap tires is between $0.5 \mathrm{~mm}$ and $1.0 \mathrm{~mm}$. The surface of the tire is not obviously damaged, and the cord layer is not cracked.

Eight groups of composite column specimens are fabricated and tested. The experimental parameters used to determine the shear behavior of the specimens are the vertical force, the relative density of the sand, and the loading mode. The tires, shape, size, and manufacturing process of the specimens remain unchanged. The lateral shear tests are conducted on the scrap tires filled with sand under five vertical forces of $100 \mathrm{kN}, 150 \mathrm{kN}, 200 \mathrm{kN}, 250 \mathrm{kN}$, and $300 \mathrm{kN}$. The dry density of the sand is $1.5 \times 10^{3} \mathrm{~kg} / \mathrm{m}^{3}$, $1.7 \times 10^{3} \mathrm{~kg} / \mathrm{m}^{3}$, and $1.9 \times 10^{3} \mathrm{~kg} / \mathrm{m}^{3}$. The loading modes are monotonic loading and cyclic loading. By comparing the specimens SD-1, SD-2, SD-3, SD-4, and SD-5, the effect of different vertical forces on the shear performance of the composite can be studied. By comparing SD-6, SD-2, and SD-7, the effect of the sand density on the shear resistance of the composite can be studied. Similarly, by comparing specimens SD-6, SD-2, and SD-7, the effect of the loading mode on the shear resistance of the composite specimens can also be investigated. The main details of the specimens are given in Table 1.

\subsection{Specimen Design}

2.2.1. Unit Design. First, the standard sand is made into sand with $10 \%$ water content. According to the "Standard for Soil Test Method" (GB/T50123), a compaction hammer made by us is used for compaction. Sand is filled into the compacting barrel in three layers. Each layer is compacted 31 times, and the compacting energy density is $2735.62 \mathrm{~kJ} / \mathrm{m}^{3}$. The homemade compaction hammer is shown in Figure 3. The weight $M$ of the hammer is $13.5 \mathrm{~kg}$, the drop distance $H$ is $685.5 \mathrm{~mm}$, the total length $L$ of the guide rod is $800 \mathrm{~mm}$, and the diameter $d$ of the compaction bottom plate of the guide rod is $153 \mathrm{~mm}$.

To improve the self-sealing and antidisturbance ability of the specimen, the rim of the mouth of the tire is cut off, as shown in Figure 4. Then, the standard sand is filled into the rubber tire, and the surface of the unit is smooth and regular after compaction, as shown in Figure 5.

2.2.2. Composite Column Specimen Design. To conveniently transport and install the specimens and improve the antidisturbance ability of the specimens during in situ debugging, a cover is set at the bottom of the three-layer composite specimen. To reduce the influence of the bottom sealing on the performance of the specimens, the thickness of the bottom sealing is limited to less than $20 \%$ of the vertical dimension of the tire unit. Combined with the specific size of the tire used in the test, the thickness of the bottom sealing is determined to be $35 \mathrm{~mm}$. The bottom of the tire is sealed with M15 mortar, and reinforcing mesh is arranged inside. The mesh is woven using $8 \mathrm{~mm}$ round bars, and the diameter of the round bars is denoted as $\Phi$. The concrete structure is shown in Figure 6.

The manufacturing steps of the sealing bottom and the composite column specimen are as follows: The first step is shown in Figure 6(a). The $8 \mathrm{~mm}$ round bars are cut to $450 \mathrm{~mm}$ each so that they can be tangent to the rim of the mouth of the tire and placed inside the tread. The truncated 8 steel bars are tied into a well-shaped reinforcing mesh and placed in the tire. The second step is shown in Figures 6(b) and $6(\mathrm{c})$. A short and thick anchorage bar with sufficient stiffness is tied on the reinforcing bar mesh and a steel mooring strand with a diameter $\Phi$ of $6 \mathrm{~mm}$ is placed through a snap in the middle of the anchoring steel bar. The tire is lifted by the steel strand, and the reinforcing mesh is temporarily consolidated with the tire. By adjusting the relative position of the steel strand clamp and anchoring steel bar, the static balance of the "tire-steel mesh-steel strand" system is ensured. The function of the steel strand is to act as a force-bearing member when the prefabricated three-layer composite column specimen is hoisted and put in place. The third step is shown in Figure 6(d). M15 mortar is filled into the system, which has achieved static equilibrium and then watering and maintenance are finished after the final setting of the mortar. Finally, the sealing work is completed. The fourth step is shown in Figures 7 and 8. First, the first tire is filled with sand, and the sand is compacted. Second, the second empty tire is placed on the first tire. The 


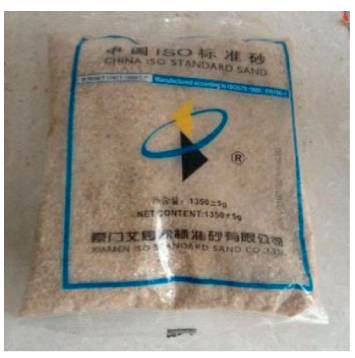

(a)

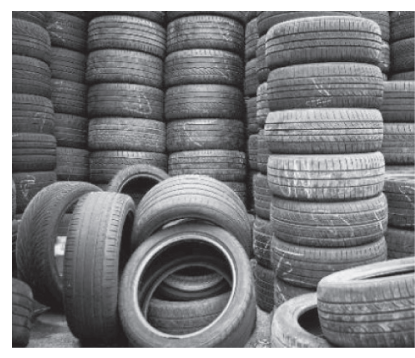

(b)

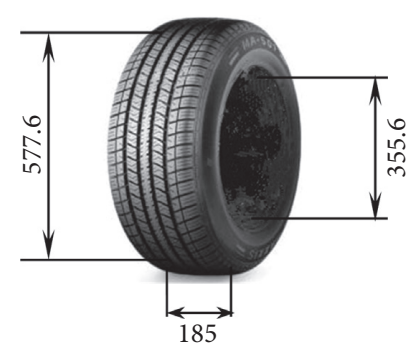

(c)

Figure 2: Test materials. (a) Standard sand. (b) Scrap rubber tires. (c) Tire size.

Table 1: Design parameters of specimens.

\begin{tabular}{lcccc}
\hline Specimen & Tire size & Vertical force $(\mathrm{kN})$ & Sand density $\left(10^{3} \mathrm{~kg} / \mathrm{m}^{3}\right)$ & Loading mode \\
\hline SD-1 & R14 & 100 & 1.7 & Monotonic loading \\
SD-2 & R14 & 150 & 1.7 & Monotonic loading \\
SD-3 & R14 & 200 & 1.7 & Monotonic loading \\
SD-4 & R14 & 250 & 1.7 & Monotonic loading \\
SD-5 & R14 & 300 & 1.7 & Monotonic loading \\
SD-6 & R14 & 150 & 1.5 & Monotonic loading \\
SD-7 & R14 & 150 & 1.9 & Monotonic loading \\
SD-8 & R14 & 150 & 1.7 & Cyclic loading \\
\hline
\end{tabular}

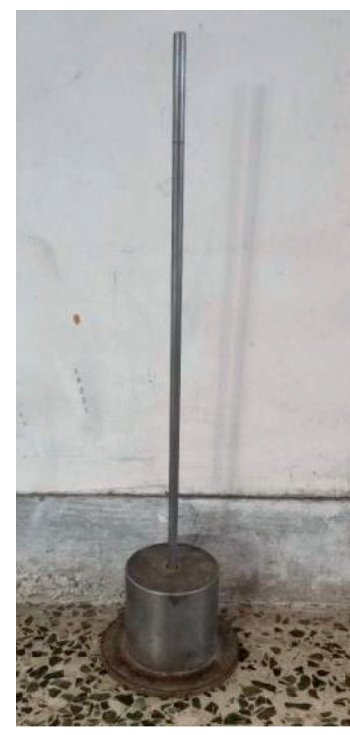

(a)

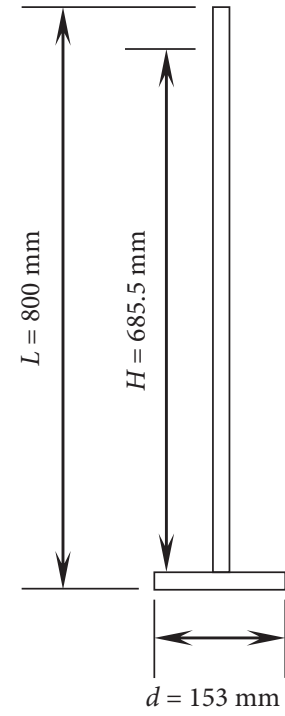

(b)

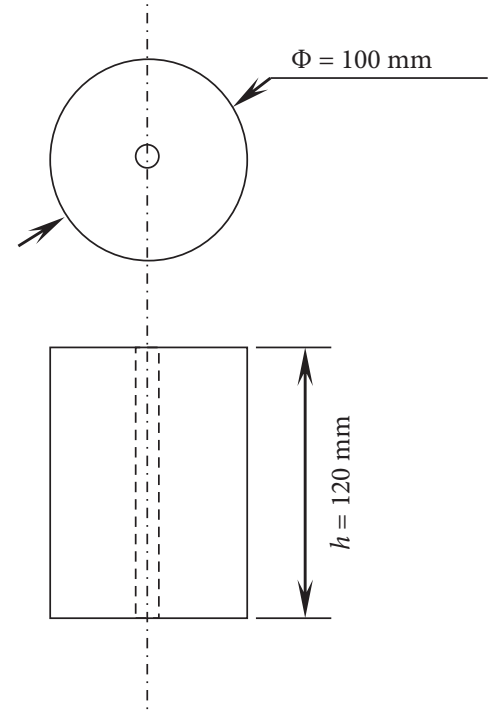

(c)

FIgURe 3: The improved hammer. (a) Material object. (b) Bottom plate of guide rod. (c) Rammer.

centerline and edge of both tires should be aligned; then sand is filled into the tire, and the sand is compacted. Third, the third empty tire is placed on the second tire. The centerline and edge of three tires should be aligned; then sand is filled into the tire, and the sand is compacted. Finally, the composite specimens are completed.

2.2.3. Test Measurements. To obtain the vertical and horizontal forces, two cylindrical tension-compression load cells are used. During the test, they are placed between the piston head of the hydraulic jack and the loading head. The range of the vertical load sensor is $0 \sim 600 \mathrm{kN}$. The range of the horizontal load sensor is $0 \sim 400 \mathrm{kN}$. The physical object is shown in Figure 9. The displacement of the specimens under external load is measured by a displacement sensor (YWD). The measuring range is $100 \mathrm{~mm}$ to $200 \mathrm{~mm}$. The output of the whole process is $20,000 \mu \varepsilon$, as shown in Figure 10 .

The load cell and displacement sensor are arranged as shown in Figure 11. The load transferred from the superstructure to the composite specimen is recorded as the vertical force $L_{1}$, and the horizontal load applied to the test 


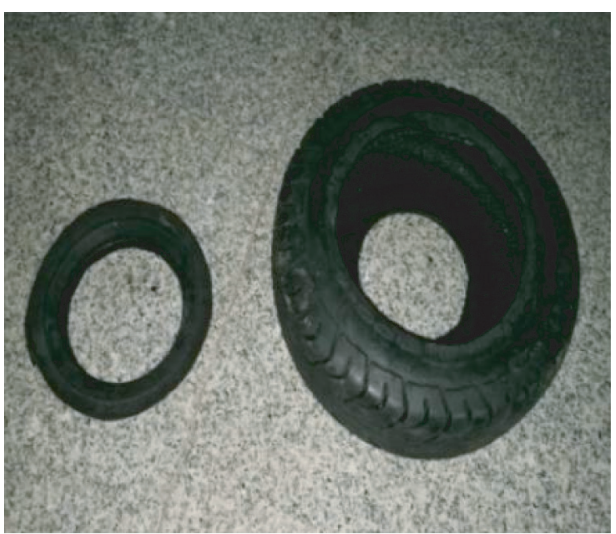

FIgURE 4: The improved tire.

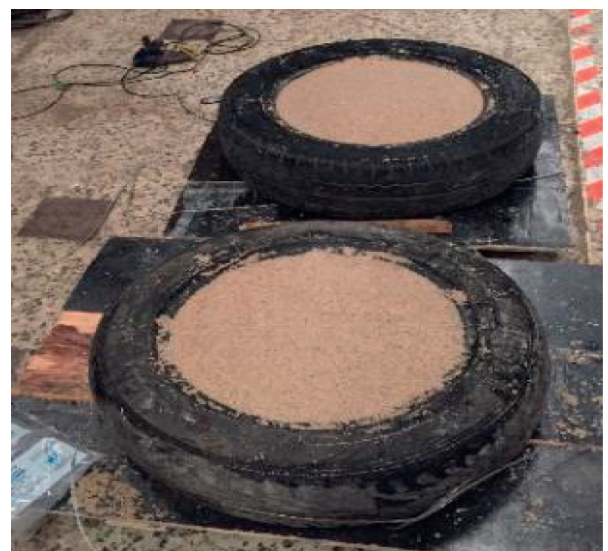

FIgURE 5: Tire-sand unit.

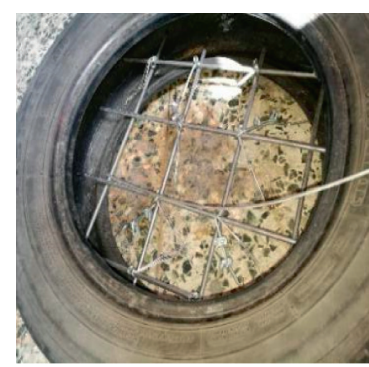

(a)

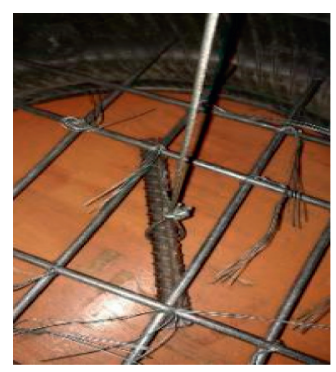

(b)

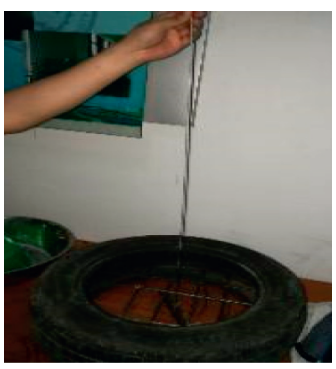

(c)

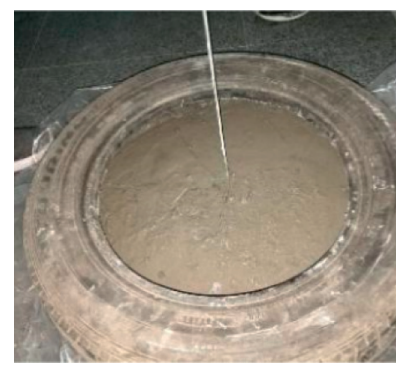

(d)

Figure 6: The concrete structure construction step of back cover.

unit is recorded as $L_{2}$. The horizontal displacement of the test unit to the ground is recorded as Disp1 and Disp2. At the same time, the two displacement meters are also used to monitor the deformation of the unit in the horizontal plane. The overall lateral deformation of the superimposed specimen driven by $L_{2}$ is recorded as Disp1, Disp3, and Disp4. The difference among the three measured values is the relative slip of the interface between the test unit and the upper and lower units. The vertical displacement of the composite specimen is recorded as Disp5 and Disp6. The measured values of these two displacement meters can reflect the compressibility of the composite specimen and the compressibility of both sides of the composite specimen during the test. At the same time, the uniformity of the compressibility can reflect the geometrical uniformity, the physical uniformity of the specimen, and the relation between the force line of the vertical force and the centroid of the specimen.

The tests are carried out in the State Key Laboratory of Structural Engineering of Shenyang Jianzhu University. A 


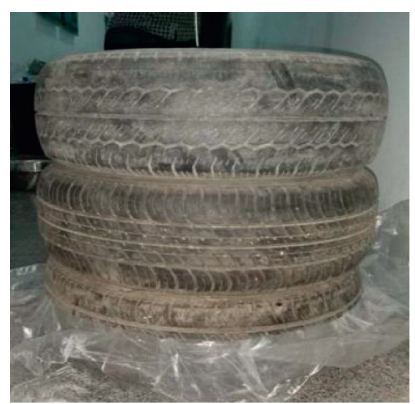

(a)

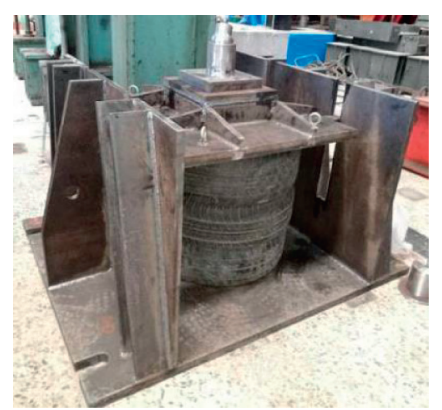

(b)

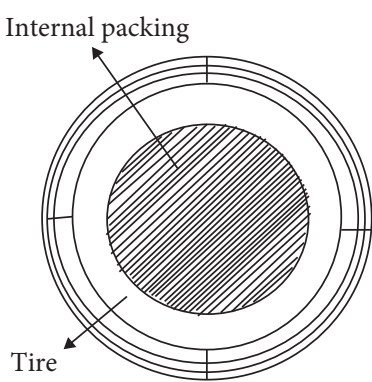

(c)

Figure 7: The final composite specimens.

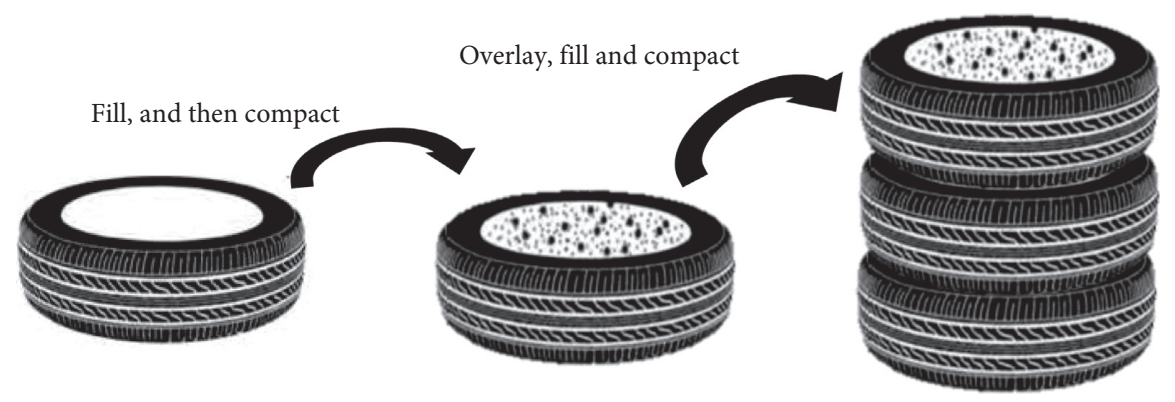

FIGURE 8: Solid structure of tires.

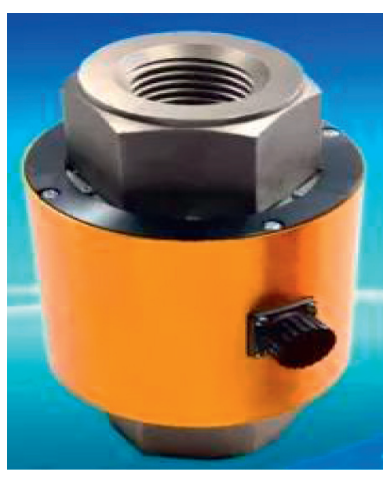

(a)

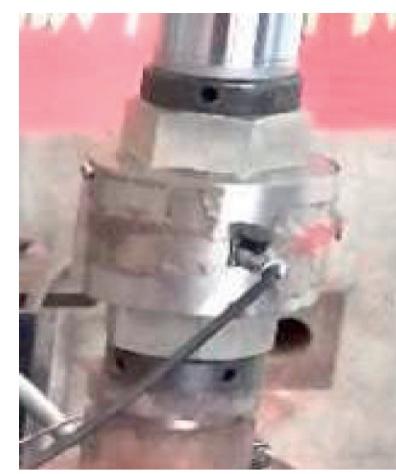

(b)

FIgURE 9: The load cell. (a) BLR-1/400. (b) BLR-1/600.

vertical force is applied on the composite column specimen by hydraulic jack. The horizontal loads are applied to the middle of the intermediate tire of the composite column specimen through a lateral hydraulic actuator. The test chamber and loading plate are welded with $30 \mathrm{~mm}$ thick steel plate. The loading device is a $9 \mathrm{~m}$ high reaction frame in the laboratory, and the vertical bearing capacity can reach $1200 \mathrm{kN}$. Oil jacks $(600 \mathrm{kN})$ with a maximum travel of $400 \mathrm{~mm}$, a displacement meter, and a measuring system are involved in the test.

2.3. Test Setup. The loading procedure of the specimens consists of two main steps. During the first stage, the hydraulic jack is used to impose a vertical load on the top of the composite specimen until the vertical force is loaded to the design value. The loading speed is $5 \mathrm{kN} / \mathrm{min}$, and the lateral load increment is $20 \mathrm{kN}$. The vertical deformation of the specimen is monitored by the displacement meter on the loading plate. When the readings of the two displacement meters on the loading plate are stable and the difference between them is not large, the constant vertical force is maintained, and the next stage of loading is carried out. In the second stage, the electrohydraulic servo actuator applies a horizontal load on the middle tire of the composite specimen. The loading speed is $2 \mathrm{~mm} / \mathrm{min}$, and there are two loading modes: monotonic loading and cyclic loading. When the horizontal load on the specimen drops below $85 \%$ of its peak value or the horizontal displacement exceeds $10 \%$ of the tire diameter (i.e., greater than $58 \mathrm{~mm}$ ), the test is stopped. 


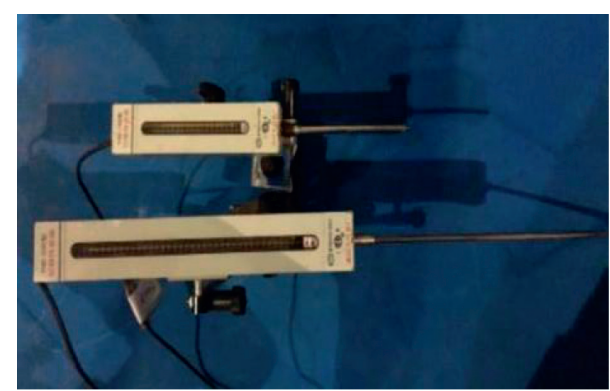

Figure 10: The displacement sensor (YWD).

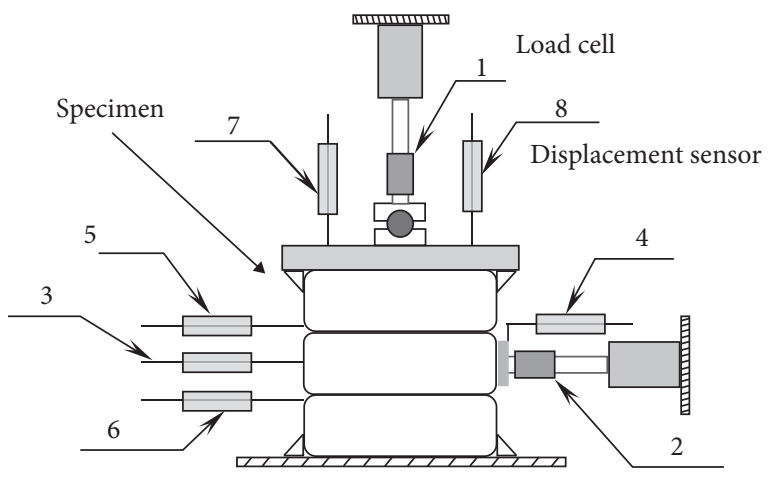

FIGURE 11: The arrangement of load cell and displacement sensor: (1) BLR-1/600, as $L_{1}$; (2) BLR-1/400, as $L_{2}$; (3) YWD-200, as Disp1; (4) YWD-200, as Disp2; (5) YWD-100, as Disp3; (6) YWD-100, as Disp4; (7) YWD-100, as Disp5; (8) YWD-100, as Disp6.

\section{Results and Discussion}

\subsection{General Observations and Failure Modes}

3.1.1. Failure Modes under Monotonic Loading. Under monotonic loading, all the specimens experienced overall flexural lateral displacement, transverse compression, and relative interfacial slip despite the different vertical loads.

From the initial stage of loading to $50 \% \sim 60 \%$ of the horizontal ultimate load, the tires of the composite specimen are closely combined. There is no relative dislocation between the test unit and its upper and lower adjacent tires, and there is no relative horizontal displacement relative to the ground. The upper and lower tires are deflected as a whole under the driving of the test unit. The test unit maintains a circular section in the horizontal direction, the three tires work together, and the vertical deformation of the specimen remains stable.

With the increase in horizontal load, the cross section of the test unit changes from circular to elliptical in the horizontal plane, and the larger the horizontal load is, the larger the proportion of the long axis to the short axis of the cross section is. The more visible relative dislocation occurs between the test unit and the interface of the adjacent upper and lower tires, and the relative dislocation is visible to the naked eye. With the loading proceeding, the change in the cross-sectional shape of the test unit and the relative dislocation between the various surfaces of the specimen continue to occur and develop until the horizontal load reaches its ultimate load.
When the horizontal load reaches its ultimate load, it then decreases slightly and then remains constant until the specimen is destroyed. At this stage, the ratio of the long and short axes in the cross section of the test unit remains unchanged, and the shear surface between the tires of each specimen has obvious relative dislocation. The test unit is pushed out. The standard sand filled in the tire leaks out along the contact surface of the tires, and the specimen is damaged. Take SD-2 as an example, as shown in Figure 12.

3.1.2. Failure Process under Cyclic Loading. Under the cyclic loading mode, a load-controlled step is adopted at the initial stage of loading. During the load-controlled stage, the lateral load increment is $20 \mathrm{kN}$ until the specimen yields. The cyclic loading mode is $0 \mathrm{kN} \longrightarrow 20 \mathrm{kN} \longrightarrow 0 \mathrm{kN} \longrightarrow 40 \mathrm{kN} \longrightarrow 0 \mathrm{kN} \longrightarrow 60 \mathrm{kN}$ and so on. Each stage is loaded and unloaded once.

From the initial stage of loading to the peak value of the horizontal load, the horizontal cross section of the test unit is roughly circular. During each stage of cyclic loading, the test unit drives the adjacent upper and lower tires to move together. In the loading stage, the specimen is deflected. In the unloading stage, the contact surfaces between the test unit and the adjacent upper and lower tires have elastic creep, and the initial slight dislocation between the two contact interfaces occurs. With the increase in the cyclic series, this kind of microdislocation accumulates continuously.

When the lateral loads reach the maximum lateral load, the test unit is noticeably pushed out. The elastic contraction suddenly occurs between the test unit and the adjacent upper and lower tire interfaces, and the direction is opposite to the direction of the horizontal loading. The horizontal displacement of the test unit increases suddenly, and then the horizontal load decreases slightly by $4 \%$. While the test unit is obviously pushed out, the standard sand filled in the tire leaks out along the contact of the two tires, and the whole specimen undergoes nonconvergent compression deformation under the action of the vertical force. Thus, the damage of the specimen is substantial, as shown in Figure 13.

When the horizontal load is completely unloaded, the horizontal displacement of specimen SD-8 is measured after it reaches a stable level. Compared with the specimens under monotonic loading, the horizontal displacement recovery of the damaged specimens under cyclic loading is smaller. The proportion of recovery is $4.14 \%$ of the residual deformation. Under the same conditions, the proportion of the horizontal displacement recovery of specimen SD-2, which is damaged under monotonic loading, is $17.21 \%$ of the residual deformation, which is 4.16 times higher than that of specimen SD8 under cyclic loading.

\subsection{Load-Displacement Curve under Monotonic Loading}

3.2.1. The Vertical Force. The horizontal load-displacement curves of the specimen are shown in Figure 14 when the dry density of the standard sand is $1.7 \times 10^{3} \mathrm{~kg} / \mathrm{m}^{3}$ and the initial 


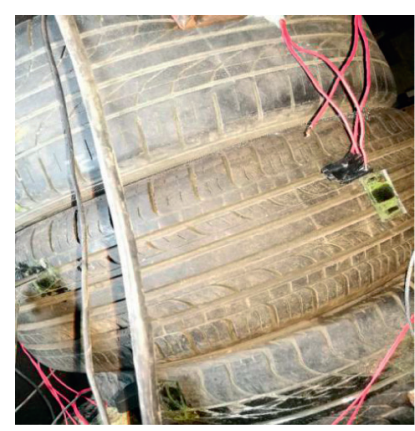

(a)

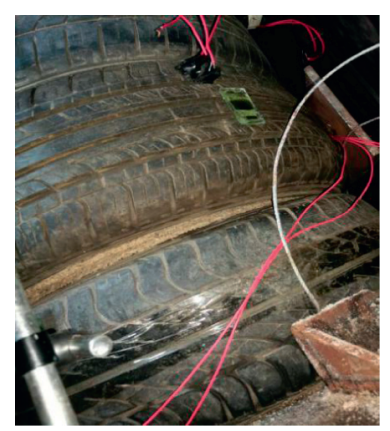

(b)

Figure 12: Failure state of specimen SD-2. (a) Misalignment between tires. (b) Sand leakage.

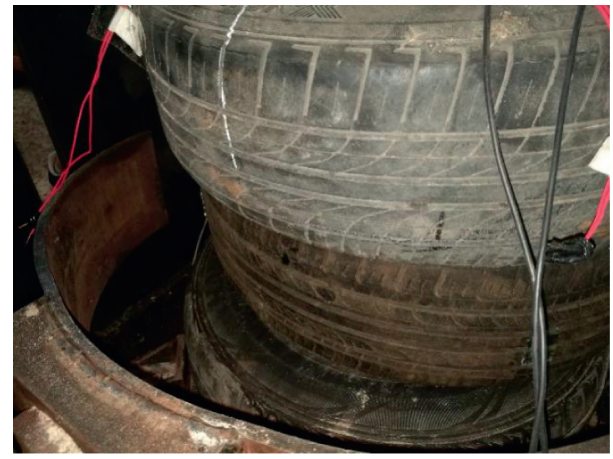

(a)

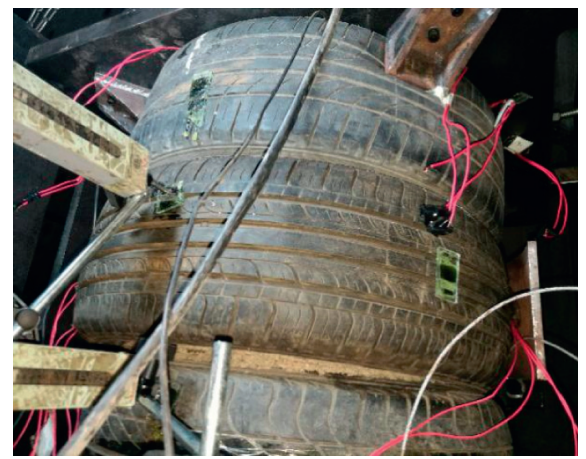

(b)

FIGURE 13: Failure state of specimen SD-8. (a) Misalignment between tires. (b) Sand leakage.

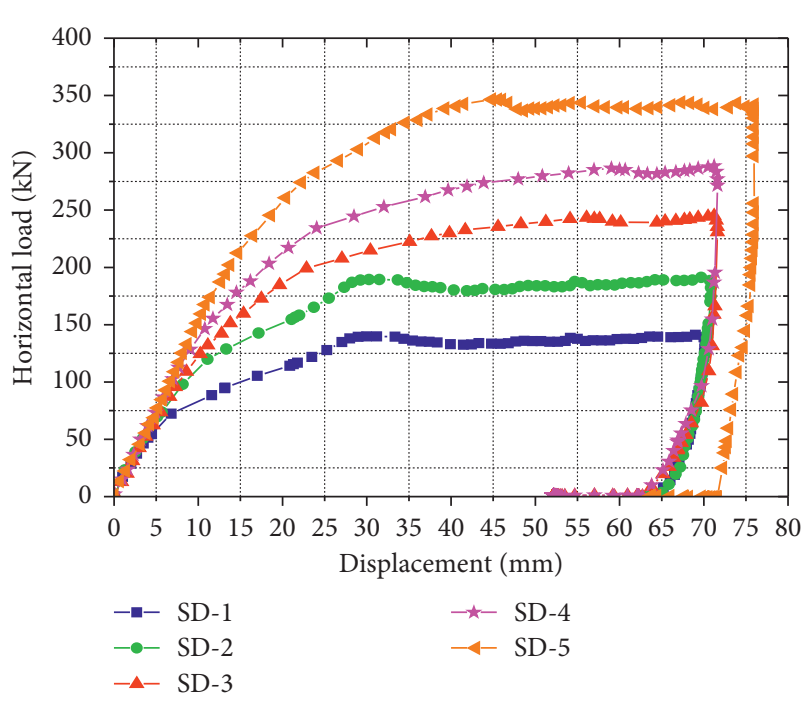

Figure 14: Curve of load displacement under monotonic load.

vertical forces are $100 \mathrm{kN}, 150 \mathrm{kN}, 200 \mathrm{kN}, 250 \mathrm{kN}$, and $300 \mathrm{kN}$.

As shown in Figure 14, the load-displacement curve patterns of the specimen are similar. At the initial stage of loading, the curve changes linearly. As the horizontal loads increase to the maximum horizontal load, the growth rate of the horizontal load begins to decrease compared with that in the previous stage, while the displacement of the specimen continues to increase. After loading to the peak load, the load-displacement curve presents a horizontal section. When the horizontal load is the same, the larger the initial vertical force is, the smaller the horizontal displacement of the specimen under the monotonic loading mode is. This shows that the lateral deformation restraint ability of the tire-sand composite increases with increasing vertical force. During the loading process, the load-displacement curve of the specimen under different vertical forces can be roughly divided into three stages.

The first stage is the elastic stage. From the initial stage of loading to $50 \% \sim 60 \%$ of the horizontal ultimate load, the horizontal load on each specimen is linear with the horizontal displacement of the specimen, and the specimen is in the stage of elastic work. When other parameters are similar, the load-deformation curve patterns of the elastic stages of the specimens with different vertical forces almost coincide. This indicates that the initial stiffnesses of the five specimens are similar. If the specimen is unloaded at this stage, most of the horizontal deformation of the specimens can be restored. Taking SD-1 as an example, its vertical force is $100 \mathrm{kN}$, as shown in Figure 15. When the horizontal displacement of specimen SD-1 is loaded to $4.47 \mathrm{~mm}$, its horizontal load is unloaded. When the unloading is completed, the residual deformation is $0.93 \mathrm{~mm}$ and the residual strain is $0.16 \%$.

The second stage is the elastoplastic stage. With the increase in the horizontal load, the load-deformation curve inclines to the abscissa axis, and the slope of the curve 


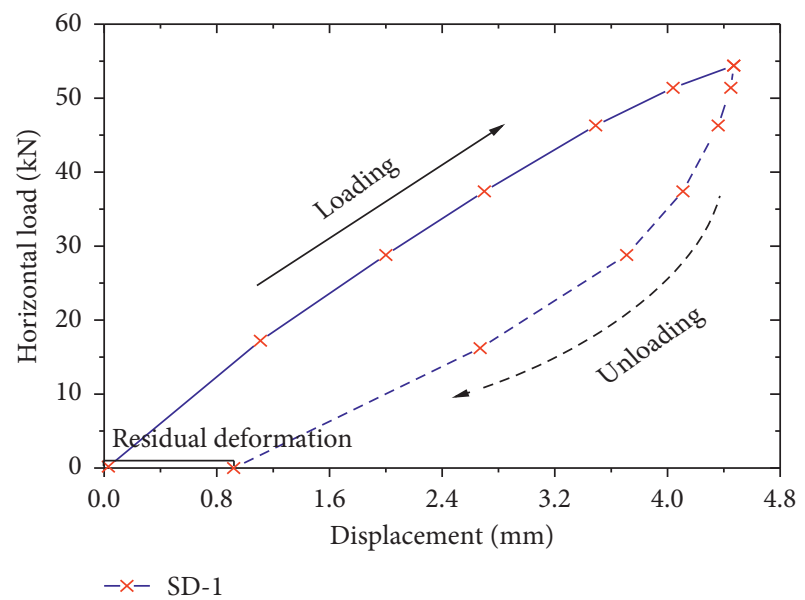

Figure 15: The load-displacement curve of elastic stage.

decreases. This trend of the load-displacement curve continues until the horizontal load reaches its ultimate load. At this stage, the curve no longer maintains a straight line, the lateral stiffness of the specimens decreases gradually, and the specimens are in the elastoplastic stage. The horizontal displacement of the specimen is mainly caused by the overall flexural lateral displacement of the specimen, the elastic creep between tire interfaces, and the deformation of the middle test unit itself in the composite column specimen. At this stage, if other parameters are the same, the slope of the load-displacement curve increases with increasing vertical force, which indicates that when the horizontal displacement of the test unit is the same, the horizontal load that the specimen can bear increases with increasing initial vertical force. This is mainly because the five tire-sand composite specimens under different working conditions have not been damaged under the initial vertical force. Because of the hoop effect of tires, the internal voids of the tire-sand composite specimen are more compacted. With the increase in the initial vertical force, the internal earth fills of the composite specimen are more compacted, and the hoop constraints of the external tire are strengthened. Therefore, the internal sand can better work in coordination with the external rubber tires. In addition, the tire structure is relatively strong, has greater elasticity, and can provide greater vertical deformation. When the vertical load reaches the peak value, there is a certain reduction in the vertical deformation of the tire-sand composite specimen after stopping loading; therefore, the friction between the tires in the composite specimen increases. For specimens SD-1 and SD-2, there is an obvious inflection point in the ascending curve, while for specimens SD-3, SD-4, and SD-5, there is no obvious inflection point in the ascending curve. The ascending curve transitions smoothly to the peak load and then gradually becomes flat. This is mainly because the tire has a great influence on the stress transfer between sand particles, and the tire can limit the lateral deformation of the sand. In addition, because the inner sand is wrapped by the tires, the vertical load on the tires is larger than that on the sand. With the increase in the initial vertical force, the tighter the inner part of the tire-sand composite is, the better the performance of the tire and sand working together is.

As shown in Figure 16, in the horizontal cross section of the test unit, $a$ is assumed to have a long axis, and its direction is the same as the direction of the horizontal load acting on the cross section, and $b$ is assumed to have a short axis, and its direction is perpendicular to the direction of the horizontal load. $\Delta$ is the difference between $b$ and the original length $(577.6 \mathrm{~mm})$ of the tire. The horizontal cross section of the test unit changes from circular to elliptical in this stage. According to the numerical reading of the displacement meters in the field test, the length changes in the long axis $a$ and the short axis $b$ of the test unit are calculated. The results are shown in Table 2. The smaller the initial vertical force is, the more substantial the cross-sectional deformation of the test unit is. The larger the initial vertical force is, the smaller the proportion of the cross-sectional deformation in the horizontal deformation is. During loading, the horizontal displacement of specimens SD-1 and SD-2 is mainly caused by the cross-sectional deformation of the test units. Therefore, the linearity of the load-displacement curve under low vertical force is better than that under high vertical force, which is mainly caused by the elastic properties between the tire and its standard sand in the process of lateral extrusion deformation. If the specimen is unloaded at this stage, a small proportion of the horizontal deformation of the specimens can be restored. Taking SD-1 as an example, its vertical force is $100 \mathrm{kN}$, as shown in Figure 17. The horizontal displacement of the SD-1 specimen is loaded to $27.05 \mathrm{~mm}$, and then its horizontal load is unloaded. When the unloading is completed, the residual deformation is $18.15 \mathrm{~mm}$, and the residual strain is $3.14 \%$, which is 19.6 times that of the previous stage.

In Figure 17, the starting point of the curve is marked as $\mathrm{O}$, the inflection point is marked as $\mathrm{A}$, the peak point is marked as $\mathrm{B}$, and the end point is marked as $\mathrm{C}$. The tangent $\mathrm{OD}$ of the curve extends through the $\mathrm{O}$ point. The ligature between the peak point and the end point of the curve is recorded as $\mathrm{BC}$, and the ligature between the starting point and the inflection point is recorded as OA. It is not difficult to find that straight line $\mathrm{BC}$ is approximately parallel to straight line OD, and the slope of both lines is larger than that of straight line OA. The slope of OD represents the initial stiffness of the specimen, and the slope of OA represents the stiffness of the elastic section. Thus, the initial stiffness of the specimen is greater than that of the elastic section, and the initial stiffness can be measured by the secant slope between the peak point and the end point.

The third stage is the plastic flow range stage. When the horizontal load reaches its ultimate load, it then decreases slightly, and the ultimate bearing capacity of each specimen decreases between $2.8 \%$ and $3.8 \%$. Then, the load remains basically constant, and the displacement increases continuously. At this time, the specimen enters the stage of plastic flow range and forms a plastic platform on the load-displacement curve.

3.2.2. The Relative Density of Sand. When the initial vertical force of the specimens is set at $150 \mathrm{kN}$ and the loading mode 


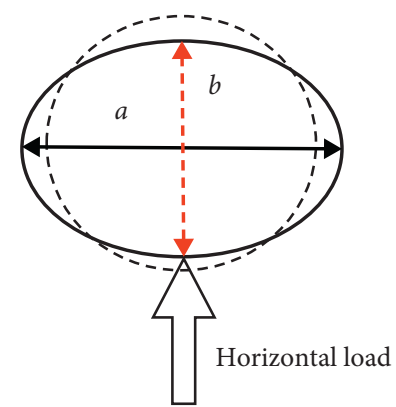

FIgURE 16: Horizontal section of test unit.

TABLE 2: Size of horizontal section of specimens.

\begin{tabular}{lcccc}
\hline Type & $\begin{array}{c}\text { The major axis } a \\
(\mathrm{~mm})\end{array}$ & $\begin{array}{c}\text { The short axis } b \\
(\mathrm{~mm})\end{array}$ & $a / b$ & $\begin{array}{c}\triangle \\
(\mathrm{mm})\end{array}$ \\
\hline SD-1 & 577.7 & 535.6 & 1.0823 & 42.0 \\
SD-2 & 580.3 & 549.6 & 1.0559 & 28.0 \\
SD-3 & 582.9 & 563.3 & 1.0348 & 14.3 \\
SD-4 & 583.8 & 572.4 & 1.0199 & 5.2 \\
SD-5 & 584.2 & 574.3 & 1.0113 & 3.3 \\
\hline
\end{tabular}

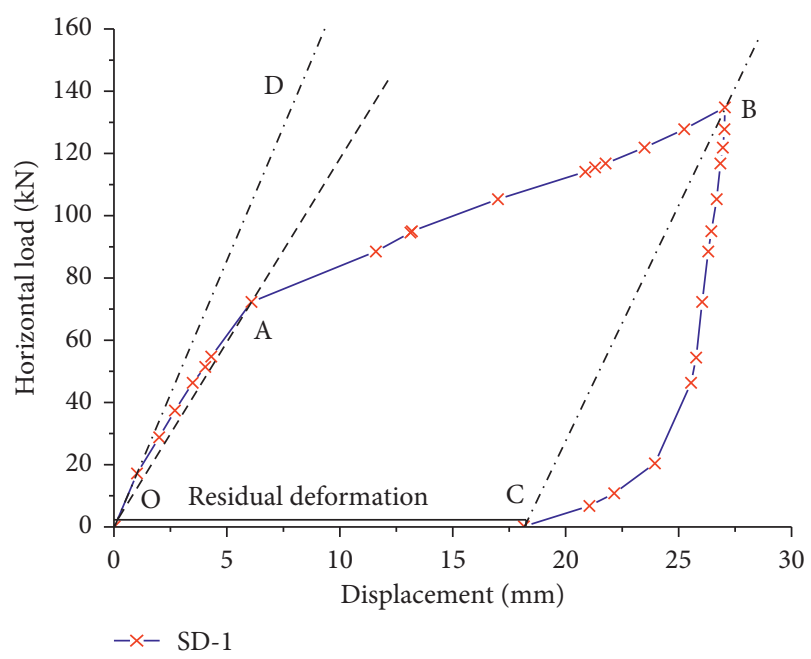

Figure 17: The load-displacement curve of elastic-plastic stage.

and other changing factors of the specimen are the same, three densities of standard sand are used to study the effect of the dry density of the sand on the load-displacement curve. The dry densities $\rho_{\mathrm{d}}$ of the standard sands are $1.5 \times 10^{3} \mathrm{~kg} /$ $\mathrm{m}^{3}, \quad 1.7 \times 10^{3} \mathrm{~kg} / \mathrm{m}^{3}$, and $1.9 \times 10^{3} \mathrm{~kg} / \mathrm{m}^{3}$. The horizontal load-displacement curves of the specimens are shown in Figure 18.

When the dry density of the sand is $1.5 \times 10^{3} \mathrm{~kg} / \mathrm{m}^{3}$, the sand in SD-6 is relatively soft, and the stiffness of the test unit in the horizontal plane is not enough to maintain its integrity under the horizontal load. At the initial stage of loading, there is a local depression at the contact point between the test unit and the loading head. With the increase in horizontal load, the degree of depression is further deepened. On the opposite side of the loading head, the test unit has only a

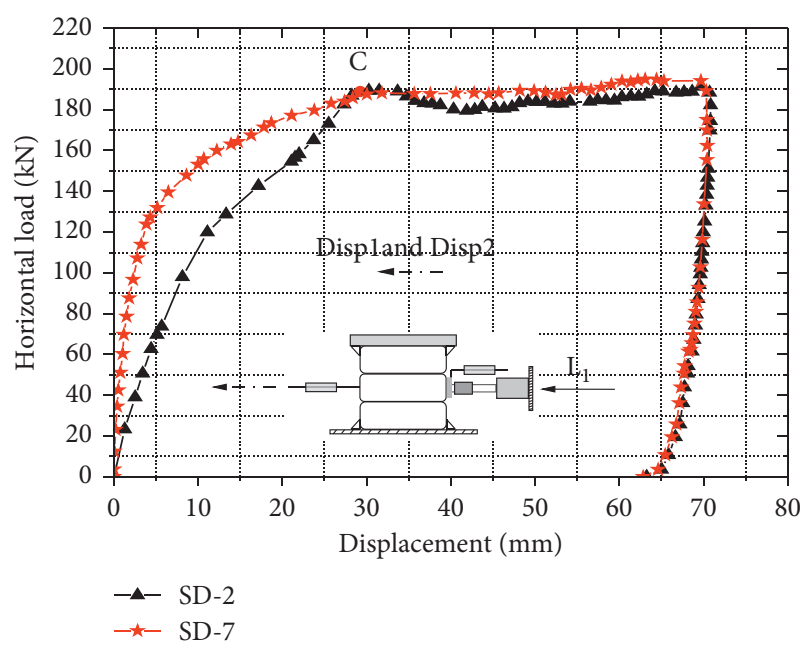

FIGURE 18: Load-displacement curve of specimen with different density.

small deformation, and there is no relative slip between the interfaces. When loading continues, the loading head is embedded in the specimen, and the standard sand filled in the tire leaks out along the gap between the loading head and the tire. At this time, the data collected by the horizontal load sensor show that the horizontal load increases slowly and tends to be stable. Because of the depression in the test unit in the horizontal plane, the quality and geometry of the composite specimen become uneven in the vertical direction. With the increase in the depression, the eccentricity of the specimen is further increased, and the tire of the composite specimen deflects. Finally, the test unit suddenly loses its stability and is squeezed out to one side. This failure process does not conform to the actual failure form of the construction foundation.

The load-displacement curves of SD-2 and SD-7 are approximately three-stage broken lines when the dry densities of the specimens are $1.7 \times 10^{3} \mathrm{~kg} / \mathrm{m}^{3}$ and $1.9 \times 10^{3} \mathrm{~kg} /$ $\mathrm{m}^{3}$, as shown in Figure 18.

In the first stage, it can be seen from the figure that the initial slope of the load-displacement curve increases with increasing sand density. The dry density of the sand increases from $1.7 \times 10^{3} \mathrm{~kg} / \mathrm{m}^{3}$ to $1.9 \times 10^{3} \mathrm{~kg} / \mathrm{m}^{3}$, the amplification is $20 \%$, and the slopes of the curves are $10.74 \mathrm{kN} / \mathrm{mm}$ and $35.05 \mathrm{kN} / \mathrm{mm}$, respectively; the amplification is $326 \%$. There is a substantial increase in the bearing capacity coupled with a substantial decrease in the horizontal deformation due to the increasing density of the sand at this stage. When the specimen is in the stage of overall flexural lateral displacement, it is evident that increasing the compactness of the sand in the tire can significantly improve the lateral stiffness of the whole specimen and enhance the overall antidisturbance ability of the composite specimen. When the other parameters are similar, the horizontal loads at the inflection point are $113.9 \mathrm{kN}$ and $119.2 \mathrm{kN}$, and the growth rate is $4.65 \%$. Therefore, the effect of increasing the compactness of the specimens on the interfacial contact properties between the tire elements is not significant. 
In the second stage, the growth rate of the horizontal load of specimen SD-7 decreases with increasing horizontal displacement. This is because the lateral displacement of the specimen is mainly caused by the deformation between the tire interfaces under the horizontal load. The deformation of the horizontal cross section of the test unit is small, and the load-displacement curve transitions smoothly to the peak load. With the increase in horizontal displacement, the growth rate of the horizontal load of specimen SD-2 is not much different from that of the first stage. This is mainly because the lateral displacement of the specimen is mainly caused by the deformation of the test unit itself under the horizontal load. The deformation of the horizontal section of the test unit is larger. The horizontal load initially increases and then decreases slightly when the load-displacement curve approaches the peak point. The curve shows an upward convex trend, which indicates that the standard sand in the test unit is squeezed and compacted. With the increase in horizontal displacement, the peak values of the load-displacement curves of the two specimens coincide approximately at point $\mathrm{C}$, and the horizontal load no longer increases with the increase in displacement, which indicates that the peak values of the horizontal load in the two cases are close when the tire-sand interface is completely damaged to form a sliding shear surface.

In the third stage, there is an obvious horizontal section on the load-displacement curve of specimen SD-7 after reaching the peak value, and the flow amplitude reaches $19.94 \mathrm{~mm}$. At this time, the horizontal load no longer increases, and the horizontal displacement increases continuously. The interface friction force and the horizontal load are approximately balanced, and the specimen moves uniformly under the condition. The force characteristics of the specimen are similar to the sliding friction of the rigid body under equilibrium force. The centered dislocation distances between the test unit and the upper and lower tires increase before failure, and the upper tire rotates under the continuous increase in eccentricity. The tire interface no longer remains level, indicating the failure of the specimen.

3.2.3. The Time Effect. According to the shape characteristics of the load-displacement curves of the specimens in the preceding chapters, the horizontal loads are set to three grades: $55 \%, 75 \%$, and $95 \%$ of the peak loads. Taking SD-2 as the research object, its vertical force is $150 \mathrm{kN}$ and the density is $1.7 \times 10^{3} \mathrm{~kg} / \mathrm{m}^{3}$. The horizontal loads on the specimens are loaded to $100 \mathrm{kN}, 140 \mathrm{kN}$, and $180 \mathrm{kN}$, and then the specimen is under sustained load. The load-displacement curves obtained under the three conditions are plotted in the same coordinate system as the load-displacement curves of specimen SD-2 under the monotonic loading mode, as shown in Figure 19.

During the loading process of specimen SD-2, the path of the load-displacement curve basically coincides under the three loading conditions, as shown in the figure. Due to the different horizontal loads, the occurrence and development of the horizontal displacement of the specimens can be divided into three modes under sustained load: the first is

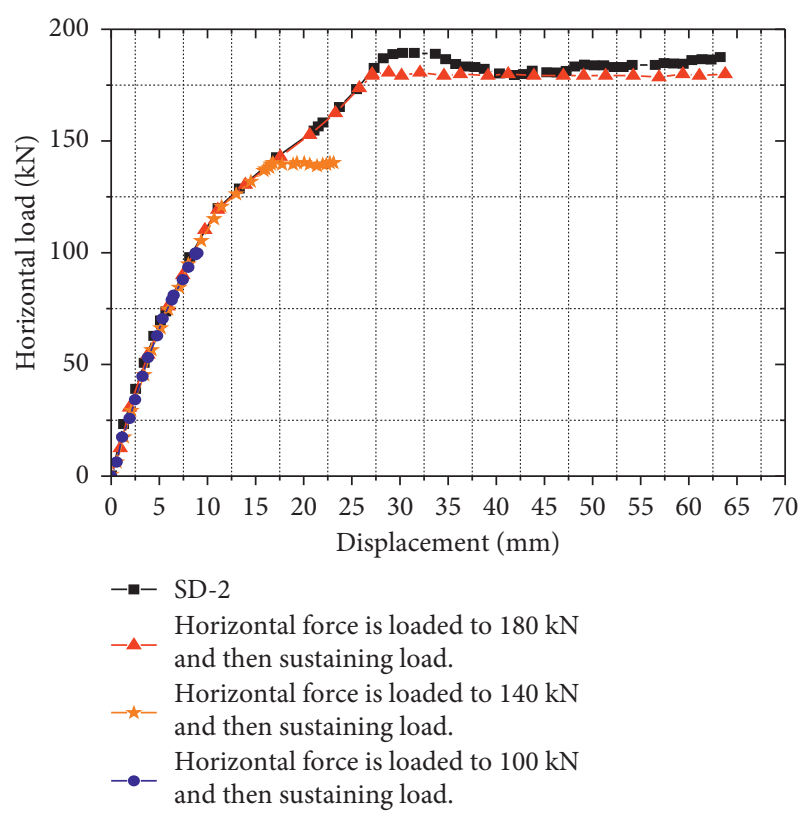

FIGURE 19: Load-displacement curve of the specimen under sustained load.

from $0 \mathrm{kN}$ to $100 \mathrm{kN}$ and then the sustaining load. Under this mode, the specimen is still in the stage of elastic work, and its load-displacement curve is approximately a straight line. During the process of the sustaining load, there is no development of the horizontal displacement of the specimen. The second mode is that specimen SD-2 is loaded to $140 \mathrm{kN}$ and then the sustaining load. Under this mode, the specimen is in the elastoplastic stage, and the horizontal displacement of the specimen increases slowly in the initial stage of loading. As time passes, the horizontal displacement of the specimen reaches stability and can be maintained. In this process, the specimens show certain creep properties, and the creep deformation is mainly due to the transition from elastic creep to interfacial slip between the tire and rubber interfaces.

The phenomenon of elastic creep is initially manifested in the drive mechanism of a belt in a mechanical engineering field. As an elastomer, the strain energy accumulated in the interior of the belt will be partially released during the process of passing the drive wheel from the tight edge to the loose edge in the transmission process. The macroscopic performance is the contraction of the stretched elastomer. In contrast, the belt passes through the driven wheel from the loose edge to the tight edge, and the belt is stretched and lengthened. The relative motion between the belt and the two pulleys occurs. The essence of this phenomenon is the stress transfer and rebalancing in the wheel-belt contact area during the transmission process. The precondition of this phenomenon is that the stress distribution in the elastic body is not uniform. As shown in Figure 20(a), the distribution of normal stress in the interface of the elastic composite is not uniform under concentrated force F. When the composite body is sheared, the external shear force acting on it is Fs, which is balanced by the frictional force between the interfaces. Macroscopically, the friction force is proportional 


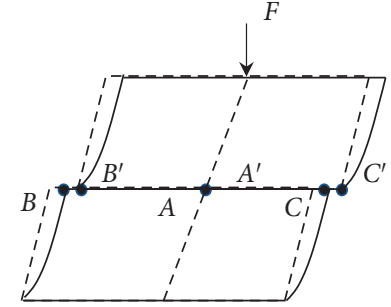

(a)

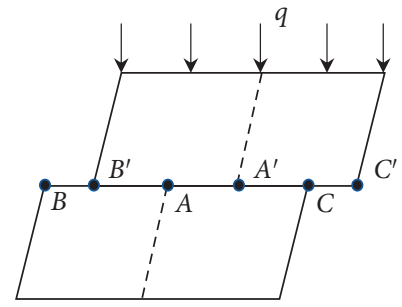

(b)

Figure 20: The connected type of section. (a) Elastic creep. (b) Interface slip.

to the normal pressure $\mathrm{N}$, which exists between the interfaces. The proportional coefficients are the static friction coefficient $\mu_{\text {st }}$ under static conditions and the sliding friction coefficient $\mu_{\mathrm{sl}}$ under sliding conditions; it is $\mu_{\mathrm{st}}>\mu_{\mathrm{sl}}$ for the same interface. In the high normal stress region, $\mu_{\mathrm{sl}} \mathrm{d} N<\mathrm{d} F_{\mathrm{s}}<\mu_{\mathrm{st}} \mathrm{d} N$. At this time, the marker points of the corresponding positions on both sides of the interface remain relatively static, such as point $A$ and point $A^{\prime}$. Meanwhile, in the low normal stress region, $\mathrm{d} F_{\mathrm{s}}>\mu_{\mathrm{st}} \mathrm{d} N$, the markers of the corresponding positions on both sides of the interface slip at this moment, such as point $B$, point $B^{\prime}$, point $C$, and point $C^{\prime}$. Such inhomogeneity causes the interface of the elastomer to creep from the high-stress zone to the lowstress zone. At this time, if the external shear force is removed, the elastomer can fully rebound and the deformation at the interface can be restored, so the local sliding between the interfaces is called elastic creep. The result of creep is that the stress distribution between interfaces tends to be uniform. As shown in Figure 20(b), the normal stress of the elastic composite specimen between the interfaces is also uniformly distributed under uniform load q. Therefore, when $F_{\mathrm{s}}>\mu_{\mathrm{st}} N$, the composite specimen will slip at the interface as a whole, and the relative positions of marker points at corresponding positions in different parts of the interface are kept parallel to each other. When the shear force is removed, the interfacial dislocation cannot be restored, and the macroscopic behavior is the plastic deformation of the composite specimen. As the stress distribution between the interfaces tends to be uniform, the elastic creep between the interfaces will transform to the interface slip, and the proportion of the plastic deformation to the total deformation will also increase.

Under the second loading mode, the standard sand filled in the high-stress zone of the tire shows certain flowability. The stress distribution between the tire and the tire-sand interface is adjusted by the flow of the standard sand so that the stress distribution between the tire rubber interfaces tends to be uniform. The elastic creep extends further toward the interface slip in the process of stress redistribution at the interface. Macroscopically, the specimens show creep characteristics. When the stress redistribution is completed, all parts of the specimens rebalance, and the creep is stable.

The third mode is that specimen SD-2 is loaded to $180 \mathrm{kN}$ and then sustained loading. Compared with the second mode, the load level of the composite SD-2 is higher and the horizontal displacement increases rapidly during the loading stage. The reason is that the higher stress state causes the strain energy of the standard sand to accumulate continuously; as a result, the local shear damage area of the tiresand contact area continues to expand. Eventually, it evolves into a shear zone that develops and penetrates along the interlayer interface of the composite specimen. At this time, the sliding friction force on the upper and lower surfaces of the test unit is almost constant, so the load-displacement curve shows a horizontal straight line, and the horizontal displacement shows a nonconvergent and continuous growth state.

3.3. Load-Displacement Curve under Cyclic Loading. The specimen SD-8 is loaded under cyclic loading. The initial vertical force is $150 \mathrm{kN}$, and the dry density of the sand is $1.7 \times 10^{3} \mathrm{~kg} / \mathrm{m}^{3}$. The test results are compared with those of specimens SD-2 and SD-7 under monotonic loading, and the effect of different loading modes on the load-displacement curve is analyzed.

Figure 21 shows the load-displacement curve of specimen SD-8 under cyclic loading. In the initial stage of loading, the upward section of the load-displacement curve is approximately a straight line, and a cusp appears at the peak value. A closed ring composed of a group of loadunload curves presents a shorter semishuttle shape. With the increase in the cycle order, the load-displacement curve near the peak point becomes smooth, and the closed loop gradually becomes full. Continuing loading, the curve eventually develops into a horizontal line approximately parallel to the coordinate axis. After unloading at each stage, the residual deformation of the specimen occurs. From the density of the curve, it can be seen that the residual deformation increases with increasing cyclic order.

To compare the effect of cyclic loading and monotonic loading on the shear failure mode of the specimens, the outer envelope of the load-displacement curve under cyclic loading is plotted in the same coordinate system as the loaddisplacement curves of specimens SD-2 and SD-7, as shown in Figure 22. The initial stiffness, inflection point position, peak value, and corresponding displacement of three groups of specimens are compared and analyzed.

The dry density of specimen SD- 8 is the same as that of specimen SD-2, which is lower than that of specimen SD-7. The slope of the load-displacement curve of specimen SD-8 


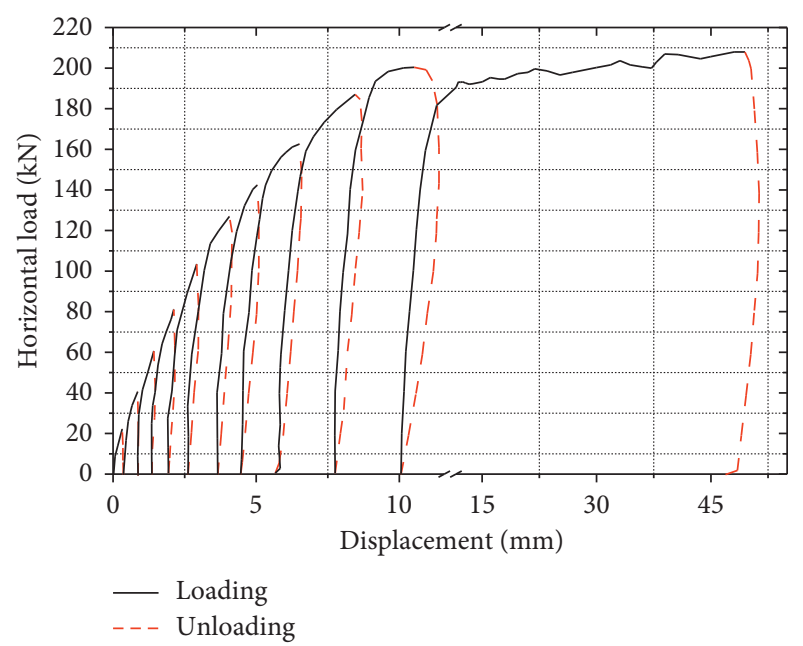

Figure 21: Load-displacement curve under cyclic load.

is obviously higher than that of specimen SD-2, which is similar to that of specimen SD-7 in the figure. The loading and unloading cyclic loading can improve the lateral stiffness of the specimen when the initial vertical force is $150 \mathrm{kN}$. When the specimen is loaded to the peak load, the horizontal bearing capacity of specimen SD-8 is higher than those of SD-7 and SD-2 by approximately $6.76 \%$.

With the increase in the horizontal load, the loaddisplacement curves of specimens SD-2 and SD-7 show inflection points. The horizontal loads at the inflection points are close to each other, and both are near $65 \%$ of the peak load. The difference in displacement is approximately $7 \mathrm{~mm}$. There is no obvious inflection point in specimen SD-8. The curve is smooth and extends to the peak point. The reason lies in the interior of the tire. The standard sand filled in the tire has a certain fluidity. After the horizontal load is unloaded, some granular materials disturbed by the horizontal load will flow and be compacted under the vertical force, which makes the transverse deformation of the test unit itself recover in the horizontal section. The whole specimen becomes more compact, uniform, and integral. Furthermore, the elastic creep between the tire interfaces can be released, and the horizontal deformation of the specimen is still dominated by the overall flexural lateral displacement when the specimens are reloaded.

With the further increase in the load, the deformation of the horizontal cross section and the elastic creep between the interfaces of the test unit can no longer be fully released during the unloading stage, and the proportion of plastic deformation in the horizontal deformation of the specimen increases. At this time, the slope of the load-displacement curve decreases and inclines to the transverse coordinate axis. When the horizontal load reaches its peak value, the shear force between the interfaces of the test unit is greater than the maximum static friction force, and the sliding friction force is less than the maximum static friction force under the same interface condition. Therefore, the load-

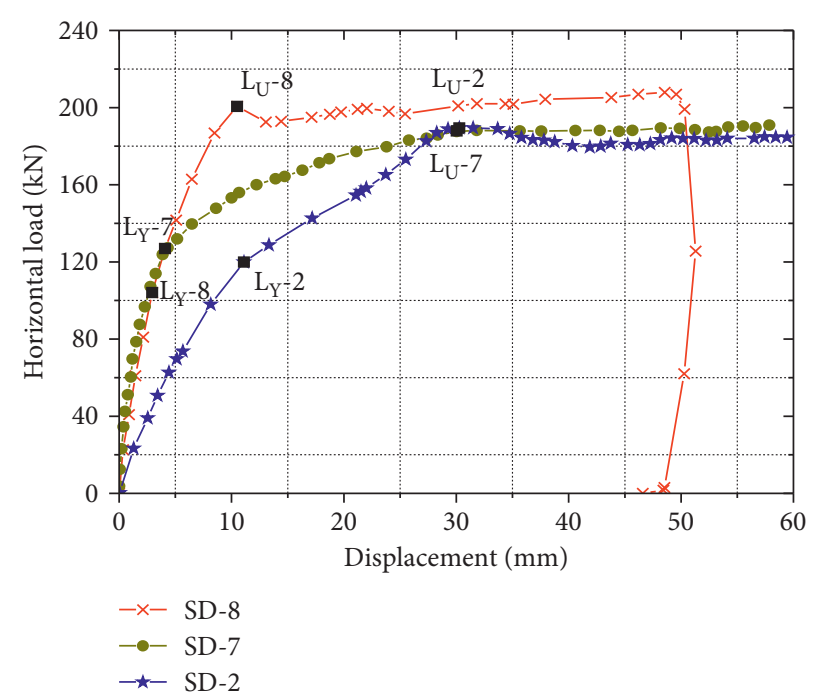

FIGURE 22: Load-displacement curve of specimens SD-2, SD-7, and SD-8.

displacement curve of specimen SD-8 first decreases slightly at the peak point and then develops horizontally, as shown in Figure 22.

Because the vertical force can make the specimen more compact and repair the shear zone in the local range through the fluidity of the granular materials during unloading, it delays the occurrence and development of the shear band at the tire-sand interface and improves the maximum bearing horizontal load of the specimen to a certain extent. The maximum bearing horizontal load of specimen SD-8 is $5.91 \%$ higher than that of specimen SD-2 and is $6.76 \%$ higher than that of specimen SD-7. If it is unloaded at the inflection point, the residual strains of SD-2 and SD-7 are $0.19 \%$ and $0.21 \%$, respectively.

As shown in Figure 22, the yield point of specimen SD-8 is defined as the position corresponding to $0.2 \%$ residual deformation after unloading. The corresponding load at the yield point is called the yield load $\left(L_{\mathrm{Y}}\right)$, and the corresponding displacement is called the yield displacement $\left(D_{\mathrm{Y}}\right)$. The corresponding load at the peak point is called the ultimate load $\left(L_{U}\right)$, and the corresponding displacement is called the ultimate displacement $\left(D_{\mathrm{U}}\right)$. The yield ratio of load is $r_{\mathrm{L}}=L_{\mathrm{Y}} / L_{\mathrm{U}}$, the yield ratio of displacement is $r_{\mathrm{D}}=D_{\mathrm{Y}} / D_{\mathrm{U}}$, and the relevant parameters of specimens SD-8, SD-2, and SD-7 are shown in Table 3.

As shown in Table 3, specimen SD-8 can bear the largest horizontal load, and its strength reserve is obviously better than those of specimens SD-2 and SD-7. Specimen SD-8 has good deformation performance under the same compactness conditions. The deformation performance of specimen SD-7 is obviously better than those of specimens SD-8 and SD-2, which shows that increasing the initial compactness of the specimens is beneficial for improving the deformation properties of the specimens, and the cyclic loading mode can significantly improve the lateral stiffness of the tire-sand composite. 
TABLE 3: The relevant parameters of specimens SD-8, SD-2, and SD-7.

\begin{tabular}{lccccc}
\hline Type & $L_{\mathrm{Y}}(\mathrm{kN})$ & $D_{\mathrm{Y}}(\mathrm{mm})$ & $L_{\mathrm{U}}(\mathrm{kN})$ & $D_{\mathrm{U}}(\mathrm{mm})$ & $r_{\mathrm{L}}$ \\
\hline SD-8 & 104.1 & 2.95 & 200.6 & 10.50 & 0.52 \\
SD-2 & 119.9 & 11.10 & 189.4 & 30.27 & 0.28 \\
SD-7 & 126.9 & 4.08 & 187.9 & 30.04 & 0.63 \\
\hline
\end{tabular}

\subsection{Mechanical Characteristic Parameters of the Composite Specimen under Shear Force}

3.4.1. Strength Envelope of Composite Specimen. Shear strength is an important index reflecting the mechanical properties of soil. In 1776, Coulomb proposed the expression of the shear strength of sand based on direct shear tests of sand, as shown in formula (1). The shear strength of soil is an important parameter in the stability analysis of soil. It has been considered that the shear strength of reinforced soil measured by the direct shear test has a linear relationship with the normal stress, which meets the Mohr-Coulomb strength theory. In this paper, the friction resistance and occlusion force between the tire and soil must be overcome if the relative sliding of the tire and soil occurs on the contact surface under a normal load. The ultimate value of the unit area formed on the contact surface is shear strength.

$$
\begin{aligned}
\tau & =\sigma \tan \varphi \quad(\text { cohesionless soil), } \\
\tau & =\sigma \tan \varphi+C \quad \text { (cohesive soil), }
\end{aligned}
$$

where $\sigma$ is the normal stress exerted on the soil unit, $\tan \varphi$ is the coefficient of the interface friction, $\varphi$ is the angle of interface friction, and $C$ is the interfacial cohesion force, which indicates the shear strength when the normal stress is zero. Its magnitude is independent of the normal stress, and, for noncohesive soil, $C=0$.

During the shear process of the composite specimen, the upper and lower surfaces of the test unit are shear planes, and the shear force $F_{S}$ on one side is half of the horizontal load $F_{\mathrm{H}}$. The normal pressure $N$ on the shear plane is equal to the vertical force $F_{\mathrm{V}}$ acting on the composite specimen. Under different vertical forces, when the horizontal load reaches its maximum value and the test unit slips relatively, the shear surface of the test unit is equal to the vertical force $F_{\mathrm{V}}$ acting on the composite specimen. Normal and shear stresses are calculated according to the following formulas:

$$
\begin{gathered}
\sigma=\frac{N}{A}=\frac{F_{\mathrm{V}}}{A}, \\
\tau=\frac{F_{\mathrm{S}}}{A}=\frac{F_{\mathrm{H}}}{2 A},
\end{gathered}
$$

where $\sigma$ is the normal stress $(\mathrm{MPa})$ on the shear plane, $\mathrm{N}$ is the normal pressure $(\mathrm{kN})$ on the shear plane, $F_{\mathrm{V}}$ is the vertical force $(\mathrm{kN})$ acting on the composite specimen, which is collected by the load sensor at the end of the vertical jack, $\tau$ is the shear stress $(\mathrm{MPa})$ on the shear plane, $F_{\mathrm{S}}$ is the shear force $(\mathrm{kN})$ on the shear plane, and $F_{\mathrm{H}}$ is the shear force $(\mathrm{kN})$ applied on the test unit. The horizontal load $(\mathrm{kN})$ is collected by the load sensor at the end of the horizontal jack. $A$ is the area of the contact surface between the two tires $\left(\mathrm{mm}^{2}\right)$.
The calculation results are listed in Table 4. In the figure of the Mohr circle of stress, the Mohr circle of stress of the soil element reaches the limit equilibrium state, which means that the points on the Mohr circle of stress are tangent to the strength envelope. The surface corresponding to the tangent point is the failure surface of the shear failure of the soil. As shown in Figure 23, the Mohr circle of stress of the standard sand element is located under the strength envelope of the test unit. The shear strength of the tire-sand structure foundation is better than that of the common standard sand.

Assuming that the relationship between shear stress and normal stress at the tire-soil interface still satisfies the Coulomb formula, the strength envelope can be expressed as follows:

$$
\tau=0.5105 \sigma+0.0705
$$

Formula (4) shows that the internal friction angle $\tan \varphi$ is $0.5105, \varphi$ is 27.04 degrees, and the cohesive force $C$ is $70.5 \mathrm{kPa}$ at the interface. The standard sand used in the test is typical cohesionless soil. The interface friction angles and the interfacial cohesion force between the tire tread and the sand for different relative densities were measured by a direct shear test. The internal friction angle $\varphi$ is 26.15 degrees, and the interfacial cohesion force $C$ is 0 . The test results show that the increase in shear strength comes from the increase in the internal friction angle and the interfacial cohesion force of the tire-sand composite specimen. The interfacial cohesion force of the tire-sand composite specimen made of standard sand in this test is called pseudocohesion. The existence of this interfacial cohesion force is due to the hoop effect of the tires on the granular materials. Under the hoop effect of the tire, the standard sand with good particle size distribution can obtain higher compactness, and the pores between particles form a capillary channel. Appropriate water content makes the channel have enough water to form a water film to adsorb to the surface of the sand particles. Under the action of additional pressure, the sand particles are bonded together, which shows the pseudocohesive force of the tiregranular material on the macro level.

3.4.2. Stress-Strain Curve of the Composite Specimen. Through formulas (2) and (3), the load-displacement curves obtained from the tests are transformed into the stress-strain curves of the specimens by calculation. The stress-strain curves of the specimens under different vertical forces, different compactness of the specimens, and different horizontal loading modes are summarized in Figure 24(a). To describe the stress-strain curves of the specimens under different influencing factors, the stress-strain data are processed without dimensions at first: 
TABLE 4: Ultimate load and the corresponding value of stress.

\begin{tabular}{lccc}
\hline Vertical force $F_{\mathrm{V}}(\mathrm{kN})$ & Horizontal load $F_{\mathrm{H}}(\mathrm{kN})$ & Normal stress $\sigma(\mathrm{MPa})$ & Shear stress $\tau(\mathrm{MPa})$ \\
\hline 100 & 139.8 & 0.382 & 0.267 \\
150 & 189.43 & 0.573 & 0.362 \\
200 & 243.53 & 0.763 & 0.465 \\
250 & 286.5 & 0.954 & 0.547 \\
300 & 346.5 & 1.145 & 0.661 \\
\hline
\end{tabular}

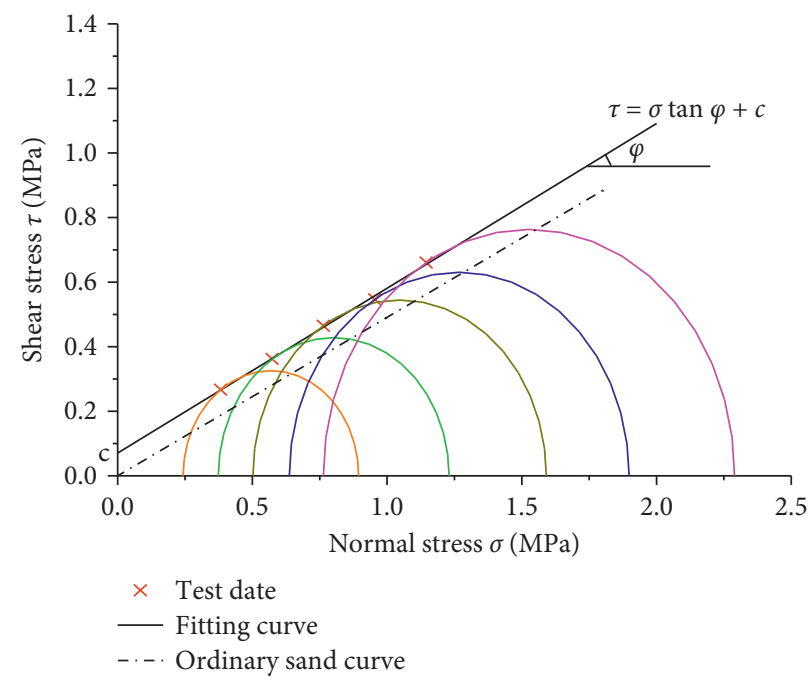

FIGURE 23: The strength envelope of specimens.

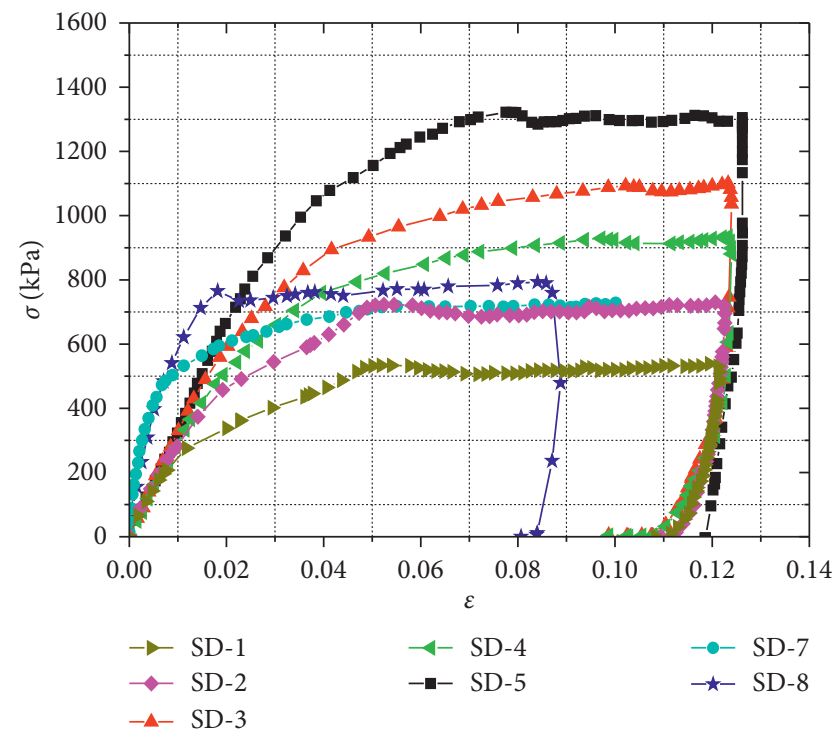

(a)

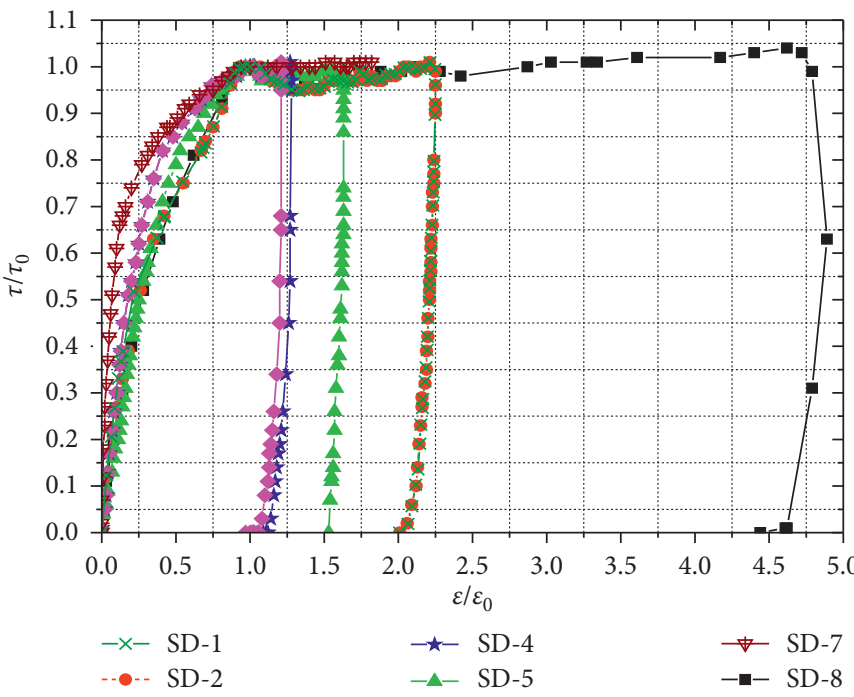

(b)

FIgURE 24: The curve of stress strain.

$$
\begin{aligned}
& x=\frac{\varepsilon}{\varepsilon_{0}}, \\
& y=\frac{\tau}{\tau_{0}},
\end{aligned}
$$

where $\tau$ is the ultimate shear stress of the specimen and $\varepsilon_{0}$ is the strain corresponding to $\tau_{0}$. The calculated values of $x$ and $y$ are plotted as curves, as shown in Figure 24(b).

Combined with the trend of the curve in Figure 24(a), the initial value of the curve is zero, and the slope 


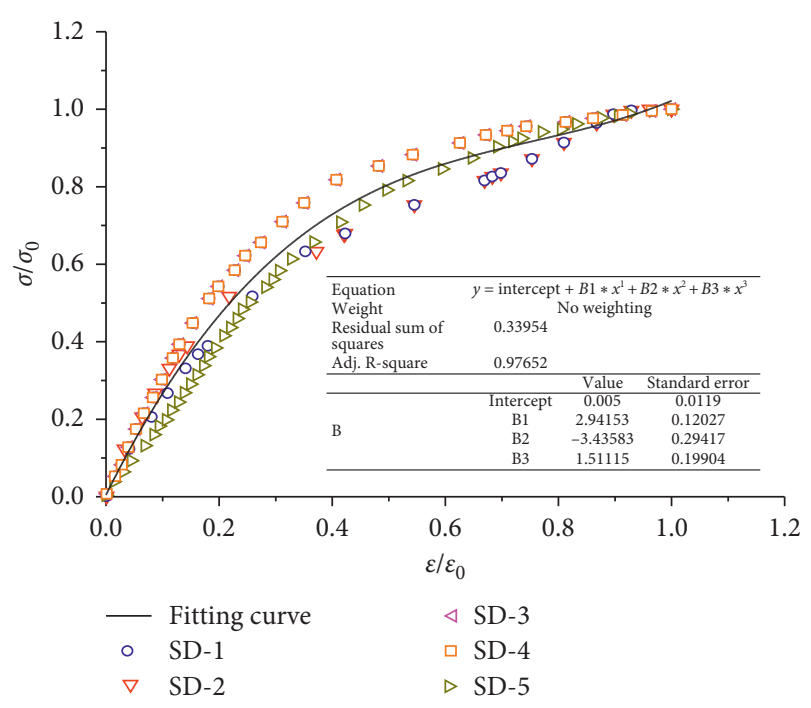

FIgURE 25: The stress-strain fitting curve of the specimen.

decreases gradually from the initial loading to the peak load. When the horizontal load reaches its peak value, the interfaces between the test unit and the upper and lower tires slip relatively, and the curve shows a plastic platform with a slope of zero. The stress-strain curve of the specimen is continuous and smooth, so the slope of the curve needs to change continuously and eventually to zero in the process of rising to the peak value. To fully describe the above characteristics of the rising section of the stress-strain curve, the constitutive equation of the rising section is expressed by a cubic polynomial as follows:

$$
y=a x+b x^{2}+c x^{3},
$$

where $a, b$, and $c$ are polynomial coefficients, which can be determined by fitting the dimensionless test data.

By fitting the stress-strain curves of the composite specimen under different vertical forces, the mathematical expression of the rising section of the curve is obtained. The correlation coefficient is 0.9765 , and the fitting effect is good. The fitting curve is shown in Figure 25, and the expression is given in the following formula:

$$
\frac{\sigma}{\sigma_{0}}=2.94\left(\frac{\varepsilon}{\varepsilon_{0}}\right)-3.436\left(\frac{\varepsilon}{\varepsilon_{0}}\right)^{2}+1.51\left(\frac{\varepsilon}{\varepsilon_{0}}\right)^{3} .
$$

As shown in Figure 25, the constitutive equation of the upward section of the stress-strain curve established above can better reflect the variations in the stress-strain behavior of the composite specimen under different vertical forces. Therefore, formula (7) gives a better description of the mechanical behavior of the composite specimen in the shear process.

\section{Conclusions}

In this paper, eight groups of three-layer single-bundle cylindrical tire-sand composite specimens were prepared and tested under shear strength tests. Different vertical forces, different densities, and different loading modes are considered to investigate and analyze the shear performance of the composite columns.

(1) All the specimens experienced overall flexural lateral displacement, transverse compression, and relative interfacial slip despite the different vertical loads under monotonic loading.

(2) Under monotonic loading, the load-displacement curve of the specimens under different vertical forces can be roughly divided into three stages: the elastic stage, the elastoplastic stage, and the plastic flow range stage. The lateral deformation restraint ability of the tire-sand composite increases with the increase in the vertical force, leading to better performance of the tire and sand working together.

(3) Under monotonic loading, increasing the compactness of the sand in the tire can significantly improve the lateral stiffness of the whole specimen and enhance the overall antidisturbance ability of the composite specimen. Under loading and unloading cyclic loading, the lateral stiffness of the specimen is significantly improved, and the horizontal loadbearing capacity of the composite specimen is also improved to a certain extent.

(4) There are two forms of relative motion between the tire and sand interface: elastic creep and interface sliding. Under the cyclic loading mode, the elastic creep ability of the element interface is helpful to restore the transverse deformation of the element during the unloading stage and to improve the overall stiffness of the specimen. The elastic creep ability depends on the elasticity of the tire rubber and the uniformity of the stress distribution between the interfaces.

(5) Under the hoop effect of the tire, the granular material with good particle gradation obtains higher compactness, and the pores between the particles form a water film, which improves the adsorption between the surfaces of the sand particles and produces pseudocohesion, which results in the shear strength of the tire-sand composite being significantly higher than that of the common standard sand.

(6) The cubic polynomial is used to describe the stressstrain variation in the composite under different vertical forces, and the mechanical behavior of the composite in the shear process is well described.

\section{Data Availability}

The data used to support the findings of this study are available from the corresponding author upon request.

\section{Conflicts of Interest}

The authors declare that there are no conflicts of interest regarding the publication of this paper. 


\section{Acknowledgments}

The research work reported in this paper was supported by the National Natural Science Foundation of China (Grant no. 51578348).

\section{References}

[1] W.-T. Tsai, C.-C. Chen, Y.-Q. Lin, C.-F. Hsiao, C.-H. Tsai, and M.-H. Hsieh, "Status of waste tires' recycling for material and energy resources in Taiwan," Journal of Material Cycles and Waste Management, vol. 19, no. 3, pp. 1288-1294, 2017.

[2] D. H. DeGroot and P. Hobart, Mexico-US Cross-Border Resolution of Waste Tire Disposal, World Environmental and Water Resources Congress, Las Vegas, NV, USA, 2007.

[3] F. Wang, X. Ping, J. Zhou, and T. Kang, "Effects of crumb rubber on the frost resistance of cement-soil," Construction and Building Materials, vol. 223, pp. 120-132, 2019.

[4] F. Belabdelouahab and H. Trouzine, "Research and enhancement of used tyres, such as material innovative in Algeria," Physics Procedia, vol. 55, pp. 68-74, 2014.

[5] H. Hazarika, E. Kohama, and T. Sugano, "Underwater shake table tests on waterfront structures protected with tire chips cushion," Journal of Geotechnical and Geoenvironmental Engineering, vol. 134, no. 12, pp. 1706-1719, 2008.

[6] X. Cheng, P. Song, X. Zhao, Z. Peng, and S. Wang, "Liquefaction of ground tire rubber at low temperature," Waste Management, vol. 71, pp. 301-310, 2018.

[7] R. Chen, L. Lun, K. Cong, Q. Li, and Y. Zhang, "Insights into pyrolysis and co-pyrolysis of tobacco stalk and scrap tire: thermochemical behaviors, kinetics, and evolved gas analysis," Energy, vol. 183, pp. 25-34, 2019.

[8] M. Serdar, A. Baričević, S. Lakušić et al., "Special purpose concrete products from waste tyre recyclates," Gradevinar, vol. 65, no. 9, pp. 793-801, 2013.

[9] J. Zeaiter, F. Azizi, M. Lameh, D. Milani, H. Y. Ismail, and A. Abbas, "Waste tire pyrolysis using thermal solar energy: an integrated approach," Renewable Energy, vol. 123, pp. 44-51, 2018.

[10] J.-W. Jang, T.-S. Yoo, J.-H. Oh, and I. Iwasaki, “Discarded tire recycling practices in the United States, Japan and Korea," Resources, Conservation and Recycling, vol. 22, no. 1-2, pp. 1-14, 1998.

[11] J. M. Reid and M. G. Winter, "The use of post-consumer tyres in Civil Engineering Sustainable waste management and recycling," in Proceedings of the Used/Post-Consumer Tyres, The Concrete and Masonry Research Group, Kingston University, London, UK, September 2004.

[12] S. Yang, B. H. Kjartanson, and R. A. Lohnes, "Structural performance of scrap tire culverts," Canadian Journal of Civil Engineering, vol. 28, no. 2, pp. 179-189, 2011.

[13] N. T. Long, "Le pneusol: recherche-réalisations-perspectives," Institut National des Science Appliquées de Lyon, Lyon, France, Thèse de Doctorat, 1993.

[14] Z. Z. Kang and B. J. Zhang, "Scrap tires recycling in landscape engineering," Advanced Materials Research, vol. 374-377, pp. 1571-1575, 2011.

[15] V. O'Shaughnessy and V. K. Garga, "Tire-reinforced earthfill. Part 3: environmental assessment," Canadian Geotechnical Journal, vol. 37, pp. 117-131, 2000.

[16] J. H. Lee, R. Salgado, A. Bernal et al., "Shredded tires and rubber-sand as lightweight backfill," Journal of Geotechnical and Geoenvironmental Engineering, vol. 125, no. 2, pp. 132141, 1999.
[17] N. He, Y. Lou, H. T. Xue et al., "Reinforcement of landslides caused by earthquake," Engineering Journal of Wuhan University, vol. 41, pp. 14-18, 2008.

[18] A. Sayão, D. Gerscovich, L. Medeiros, and A. Sieira, "Scrap tire-an attractive material for gravity retaining walls and soil reinforcement," The Journal of Solid Waste Technology and Management, vol. 35, no. 3, pp. 135-155, 2009.

[19] P. S. H. Poh and B. B. Broms, "Slope stabilization using old rubber tires and geotextiles," Journal of Performance of Constructed Facilities, vol. 9, no. 1, pp. 76-79, 1995.

[20] V. K. Garga and V. O’Shaughnessy, "Tire-reinforced earthfill. Part 1: construction of a test fill, performance, and retaining wall design," Canadian Geotechnical Journal, vol. 37, no. 1, pp. 75-96, 2000.

[21] V. O'Shaughnessy and V. K. Garga, "Tire-reinforced earthfill. Part 2: pull-out behaviour and reinforced slope design," Canadian Geotechnical Journal, vol. 37, pp. 117-131, 2000.

[22] K. S. Kim, Y. W. Yoon, G. L. Yoon et al., "Pullout behavior of cell-type tires in reinforced soil structures," KSCE Journal of Civil Engineering, vol. 15, no. 7, pp. 1209-1217, 2011.

[23] Y. W. Yoon, S. H. Cheon, D. S. Kang et al., "Bearing capacity and settlement of tire-reinforced sands," Geotextiles and Geomembranes, vol. 22, no. 5, pp. 439-453, 2004.

[24] J. G. Zornberg, A. R. Cabral, and C. Viratjandr, "Behaviour of tire shred-sand mixtures," Canadian Geotechnical Journal, vol. 41, no. 2, pp. 227-241, 2004.

[25] H. J. Lee and H. S. Roh, "The use of recycled tire chips to minimize dynamic earth pressure during compaction of backfill," Construction and Building Materials, vol. 21, no. 5, pp. 1016-1026, 2007.

[26] S. B. Reddy and A. M. Krishna, "Mitigation of dynamic loading effects on retaining walls using recycled tire chips," Lecture Notes in Civil Engineering, vol. 15, pp. 141-148, 2019.

[27] S. Hossain and P. W. Jayawickrama, Use of Whole Tires in Earth Retaining Structures, Center for Multidisciplnary Research inTransportation Texas Tech University, Lubbock, TX, USA, 2000.

[28] M. R. Hausmann, "Slope remediation," in Proceedings of the Conference Stability and Performance of Slopes and Embankments II, vol. 2, pp. 1274-1317, ASCE, Berkeley, CA, USA, June-July 1992.

[29] B. B. K. Huat, A. A. Aziz, L. W. Chuan et al., "Application of scrap tires as earth reinforcement for repair of tropical residual soil slope," Journal of Geotechnical and Geoenvironmental Engineering, vol. 13, pp. 1-9, 2008.

[30] F.-C. Wang, J. Li, Z.-H. Lin, P.-P. Tian, and H.-Y. Zhao, "Research on hoop capacity of composite foundation of discarded rubber tires," European Journal of Environmental and Civil Engineering, pp. 1-23, 2019.

[31] Y. Lu, S. H. Liu, Y. Z. Zhang et al., "Experimental study on horizontal cyclic shear and vertical excitation behavior of STC reinforced sand," China Earthquake Engineering Journal, vol. 37, no. 2, pp. 494-499, 2015.

[32] Y. M. Wang, Y. Lu, T. Wang et al., "Experimental and numerical study of scrap tire columns filled with different geomaterials under cyclic shear," Journal of Yangtze River Scientific Research Institute, vol. 36, no. 1, pp. 117-122, 2019. 